\title{
Climate impacts of recent multidecadal changes in Atlantic Ocean Sea Surface Temperature: a multimodel comparison
}

\author{
Daniel L. R. Hodson - Rowan T. Sutton • \\ Christophe Cassou · Noel Keenlyside · \\ Yuko Okumura · Tianjun Zhou
}

Received: 27 October 2008/Accepted: 29 March 2009/Published online: 14 April 2009

(C) Springer-Verlag 2009

\begin{abstract}
During the twentieth century sea surface temperatures in the Atlantic Ocean exhibited prominent multidecadal variations. The source of such variations has yet to be rigorously established-but the question of their impact on climate can be investigated. Here we report on a set of multimodel experiments to examine the impact of patterns of warming in the North Atlantic, and cooling in the South Atlantic, derived from observations, that is characteristic of the positive phase of the Atlantic Multidecadal Oscillation (AMO). The experiments were carried out with six atmospheric General Circulation Models (including two versions of one model), and a major goal was to assess the extent to which key climate impacts are consistent between the different models. The major climate impacts are found over North and South America, with the
\end{abstract}

D. L. R. Hodson $(\bowtie) \cdot$ R. T. Sutton

Walker Institute, Department of Meteorology,

University of Reading, P.O. Box 243, Earley Gate,

Reading RG6 6BB, UK

e-mail: d.1.r.hodson@ reading.ac.uk

C. Cassou

CERFACS, 42, Avenue Gaspard Coriolis, Toulouse Cedex

31057, France

N. Keenlyside

IFM-GEOMAR, Dusternbrooker Weg, 20, Kiel 24105, Germany

Y. Okumura

CAS, CGD-NCAR, P.O. Box 3000 Boulder,

CO 80307-3000, USA

T. Zhou

State Key Laboratory of Numerical Modeling for Atmospheric Sciences and Geophysical Fluid Dynamics, Institute of Atmospheric Physics, Chinese Acadamey

of Sciences, Beijing, China strongest impacts over land found over the United States and northern parts of South America. These responses appear to be driven by a combination of an off-equatorial Gill response to diabatic heating over the Caribbean due to increased rainfall within the region and a Northward shift in the Inter Tropical Convergence Zone (ITCZ) due to the anomalous cross-equatorial SST gradient. The majority of the models show warmer US land temperatures and reduced Mean Sea Level Pressure during summer (JJA) in response to a warmer North Atlantic and a cooler South Atlantic, in line with observations. However the majority of models show no significant impact on US rainfall during summer. Over northern South America, all models show reduced rainfall in southern hemisphere winter (JJA), whilst in Summer (DJF) there is a generally an increase in rainfall. However, there is a large spread amongst the models in the magnitude of the rainfall anomalies over land. Away from the Americas, there are no consistent significant modelled responses. In particular there are no significant changes in the North Atlantic Oscillation (NAO) over the North Atlantic and Europe in Winter (DJF). Additionally, the observed Sahel drying signal in African rainfall is not seen in the modelled responses. Suggesting that, in contrast to some studies, the Atlantic Multidecadal Oscillation was not the primary driver of recent reductions in Sahel rainfall.

Keywords Atlantic $\cdot$ MOC $\cdot$ Decadal

\section{Introduction}

Historical observations show that over the last century or so Atlantic Ocean Sea Surface Temperatures (SST) have exhibited a large-scale pattern of multi-decadal variation 
that is characterised by anomalies of one sign in the Northern Hemisphere, and anomalies of the opposite sign in the Southern Hemisphere, i.e. an interhemispheric dipole. This dipolar pattern may be a signature of variations in the Atlantic Meridional Overturning Circulation (AMOC) (Knight et al. 2005; Knight 2008), possibly manifesting as a potentially predictable "Atlantic Multidecadal Oscillation" (AMO). This pattern may also be influenced by changes in external forcing by aerosols and greenhouse gases (Rotstayn and Lohmann 2002).

These multidecadal variations in Atlantic SST are important because they have been linked to significant impacts on climate in many regions: the Americas, Africa, and Eurasian continent (Wang et al. 2004). Impacts for which there is specific evidence include modulation of rainfall in the Nordeste region of Brazil and the Sahel region of North Africa, influences on the summertime climate of North America, and influences on the genesis of Atlantic Hurricanes (e.g. Folland et al. 1986; Shapiro and Goldenberg 1998; Uvo et al. 1998; Zhou and Lau 2001; Enfield et al. 2001; Goldenberg et al. 2001; McCabe et al. 2004; Sutton and Hodson 2005, 2007; Knight et al. 2006).

In previous work Sutton and Hodson (2007) we used experiments with an atmospheric General Circulation Model (GCM) to study the impacts of multidecadal variations in North Atlantic SSTs in some detail, examining in particular the seasonal variation of the climate response. We found that in all seasons this response is strongest, in the sense of highest signal-to-noise ratio, in the tropics. The strongest (large-scale) response was found in boreal summer, and this response included significant impacts on rainfall, temperature and sea level pressure over North America, as described in Sutton and Hodson (2005).

The experiments described in Sutton and Hodson (2005) (henceforth SUT05) and Sutton and Hodson (2007) involved forcing the atmospheric GCM with idealised SST anomalies, designed to be representative of the observed multidecadal variations in Atlantic SST. However, there was no seasonal variation in the SST anomalies and, in order to increase signal-to-noise, the amplitude of the anomalies was unrealistically large. Because of these limitations, part of the motivation for the present study is to examine whether any of our previous conclusions concerning the climate impact of Atlantic SSTs may be sensitive to using more realistic SST anomalies. In addition, however, this study has a second, more important, motivation. Our previous work was conducted with a single atmospheric GCM. It is increasingly recognised that model uncertainty is a critical factor which must be considered in the assessment of any climate impacts. Therefore, a major goal of this study is to investigate and quantify the extent to which the impacts of multidecadal variations in Atlantic SST are consistent, or otherwise, between different atmospheric GCMs. To address this goal, the paper is based on a set of identical experiments with six different atmospheric GCMs (including two versions of one GCM). These experiments were made possible by a collaboration supported by the EU-funded DYNAMITE project.

The structure of the paper is as follows. In Sect. 2 we discuss the models used in this study, the experimental design and the observational data. In Sect. 3, we present the results of the experiments and draw comparisons with observations in Sect. 4. These results and comparisons are then discussed in greater detail in Sect. 5. Finally in Sect. 6, we summarise findings and draw conclusions.

\section{Experiments and observational data}

\subsection{Models}

Five Atmosphere General Circulation Models (AGCMs) were used in this study:

- Arpege-climate Déqué et al. (1994) has been developed at Météo France from the Arpege/IFS operational model developed by Météo France and ECMWF. It is a T63 spectral model with 31 hybrid levels in the vertical.

- The Community Atmosphere Model (CAM3) Collins et al. (2006) has been developed by the climate community in collaboration with the National Center for Atmospheric Research (NCAR). For this study, CAM3 was configured to use a T42 spectral truncation-an approximate horizontal resolution of $2.8^{\circ}$ latitude $\times 2.8^{\circ}$ longitude, and with 26 levels in the vertical.

- Echam5 Roeckner et al. (2006) has been developed by Max Planck Institute in Hamburg from a version of the ECMWF model. It is a T63 spectral model with effective horizontal resolutions of $1.875^{\circ}$ latitude $\times 1.875^{\circ}$ longitude and with 31 hybrid levels in the vertical.

- The Grid Atmosphere Model of IAP/LASG (GAMIL) Li et al. (2007) has been developed by the Institute of Atmospheric Physics at the Chinese Academy of Science (IAP) and the State Key Laboratory of Numerical Modelling for Atmospheric Science and Geophysical Fluid Dynamics. It is based on NCAR CAM2 (the precursor to CAM3) with a new dynamical core developed by IAP/LASG. For these experiments the model was run with a horizontal resolution of $2.8^{\circ}$ latitude $\times 2.8^{\circ}$ longitude and 26 levels in the vertical.

- HadAM3 Pope et al. (2000) is a version of the UK Hadley Centre global atmosphere circulation model. HadAM3 employs an Arakawa B grid with a horizontal 
resolution of $2.5^{\circ}$ latitude $\times 3.75^{\circ}$ longitude and 19 hybrid levels in the vertical.

\subsection{Observational datasets}

Four observational datasets were used for this study. Sea surface temperatures (SSTs) and Sea Ice Coverage were taken from the HadISST dataset; a dataset reconstructed from observations using a two stage reduced-space optimal interpolation procedure (Rayner et al. 2003). The Mean Sea Level Pressure dataset, HadSLP1 was also produced by a reduced-space optimal interpolation procedure (Basnett and Parker 1997). Land surface temperature data were provided by HadCRUT3-a gridded dataset of global historical surface temperature anomalies produced by the Met Office Hadley Centre and the Climatic Research Unit at the University of East Anglia (Brohan et al. 2006). All these datasets are available at http://www.hadobs.com. Finally, the gridded precipitation dataset was provided by Mike Hulme of the Climatic Research Unit at the University of East Anglia (Hulme 1992).

\subsection{Experiments}

The studies presented in Sutton and Hodson (2005) and Sutton and Hodson (2007) examined the response of the climate to a large warming of the North Atlantic derived from observed changes in North Atlantic SST. In those studies HadAM3 was forced with a North Atlantic SST anomaly pattern derived by regressing annual mean observed North Atlantic SSTs (1871-2003), onto a low pass filtered index of annual mean North Atlantic SST. The resulting anomaly was multiplied by four, before being used to force HadAM3. The motivation behind this scaling was an attempt to increase signal to noise. The results were then scaled by $1 / 4$ before comparison with observations. Two potential shortcomings of this experiment are the implicit assumption of linearity associated with the anomaly scaling procedure and the lack of a seasonal cycle in the SST anomaly.

In this paper we therefore seek to improve on these previous studies by using more realistic SST forcing. Firstly, we do not apply any artificial scaling to the SST patterns used to force the models; they are derived directly from the observed SSTs. Secondly, to examine the impact of seasonal variations in Atlantic SST, we force the models with monthly mean, rather than annual mean, SST anomalies. Additionally, we expand the region of the Atlantic Ocean under investigation. We include both the South Atlantic SSTs (to 40S) and the North Atlantic SSTs up to the seasonal ice edge. In order to be consistent with the SSTs at the ice edge, we also force the model with monthly mean Sea Ice Fraction (SIF).
We performed two experiments, corresponding to cool and warm phases of the North Atlantic Ocean (see Fig. 1a). For the first experiment (CNTL), the model was forced with monthly mean global SST and SIF climatologies. These climatologies were formed by averaging observed SST and SIF from the HadISST dataset (Rayner et al. 2003) between 1961 and 1990. For the second experiment (AP), the model was forced with monthly mean observed SST and SIF averaged between 1951 and 1960 in the Atlantic region (to $40 \mathrm{~S}$, with a northern boundary at the sea-ice edge), and SST and SIF climatologies elsewhere. A cosine-squared smoothing was applied along the boundaries of the SST field to prevent discontinuities in the gradient.

Previously in Sutton and Hodson (2005), the warm North Atlantic period was chosen to be 1931-1961. The shorter time period used in this study (1951-1960), arose as a consequence of extending the SST pattern to include the Atlantic up to the northern sea-ice edge. The sea ice (SIF) data in the North Atlantic before 1951 is unreliable and hence, to maintain consistency with the SST data, we were constrained to use only SST data since 1951.

Figure $1 \mathrm{~b}$ and $\mathrm{c}$ show the differences in global SST between the earlier warm Atlantic period and the later cool Atlantic period, for the two definitions of the warm Atlantic period used in Sutton and Hodson (2005) and this study. The figures demonstrate that this choice does not change the large scale structure of the SST pattern in the Atlantic. There are, however, significant differences outside the Atlantic, most notably in the Indian Ocean and in the North West Pacific, east of Japan. Such differences need to be considered when the model results are compared with observed changes between the two periods. Any inconsistencies may arise as a consequence of SST forcing from these regions. Inconsistencies may also arise due to other differences between these two periods, for example concentrations of greenhouse gases and aerosols.

The seasonal evolution of the differences between these two SST patterns (AP-CNTL) is shown in Fig. 2. Whilst the large scale dipole structure of the SST pattern is preserved throughout the year, there are significant smaller scale features that display monthly variations. In particular, the strong warm anomaly south of Greenland and the cold anomaly off the west coast of southern Africa.

Both CNTL and AP experiments were integrated for 40 years (80 years for Arpege and HadAM3). ${ }^{1}$ We assume that a given month in 1 year is statistically independent from the same month in the following year. And hence we consider the 40 (80) years to be 40 (80) ensemble

\footnotetext{
1 The results for Arpege and HadAM3 presented here are not markedly different if 40 of the 80 years of data are used in the following analyses.
} 
Fig. 1 a Index of the North Atlantic SST 1871-2003 (HadISST averaged between $7.5-75 \mathrm{~W}$ and $0-60 \mathrm{~N})$. The dashed line is the same index smoothed with a 10 year running mean. b SST

differences between 1931:1960 mean and 1961:1990 mean. c SST differences between 1951:1960 mean and 1961:1990 mean. Regions not significant at the $95 \%(p>0.05)$ level are shaded white
Fig. 2 SST anomalies: differences between the AP (1951-1960) and CNTL (1961-1990) SST forcing patterns for a January, b April, c July and d October. Units are ${ }^{\circ} \mathrm{C}$. Regions of the ocean that are covered with sea ice in both periods are shaded white
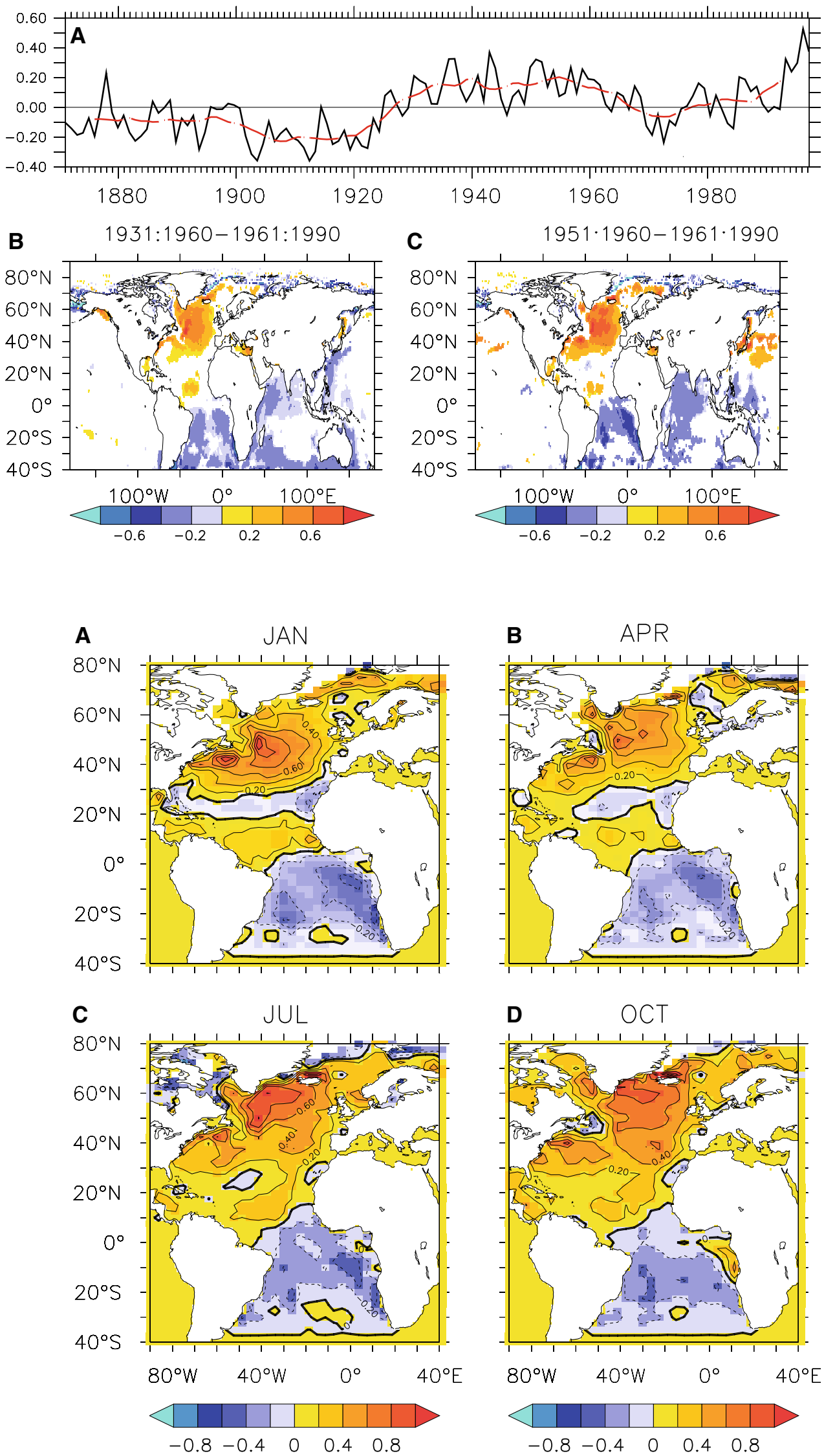
members-each independent responses to the common forcing. The mean of the 40 (80) ensemble members is an unbiased estimate of the true response of the model atmosphere to the SST and Sea Ice forcing fields. The statistical significance of this response is then tested using a $t$-test.

\section{Results}

In this section we compare and examine each model's response to the warm North Atlantic SST anomaly described in Sect. 2.3. To examine the seasonal dependence of the responses, we will focus on both Boreal
Summer (JJA) and Boreal Winter (DJF). In order to draw comparisons with the results presented in Sutton and Hodson $(2005,2007)$ we will begin by considering the modelled responses of the Mean Sea Level Pressure (MSLP), precipitation and surface air temperature.

\subsection{Boreal summer}

Figure 3 shows the modelled response (AP-CNTL) of Mean Sea Level Pressure (MSLP), precipitation and 2-m air temperature during Boreal Summer (JJA). All models show a significant high pressure signal over the South Atlantic Ocean-over the region of imposed cooling. There is also a region of significant low pressure extending from
A $80^{\circ} \mathrm{N}$
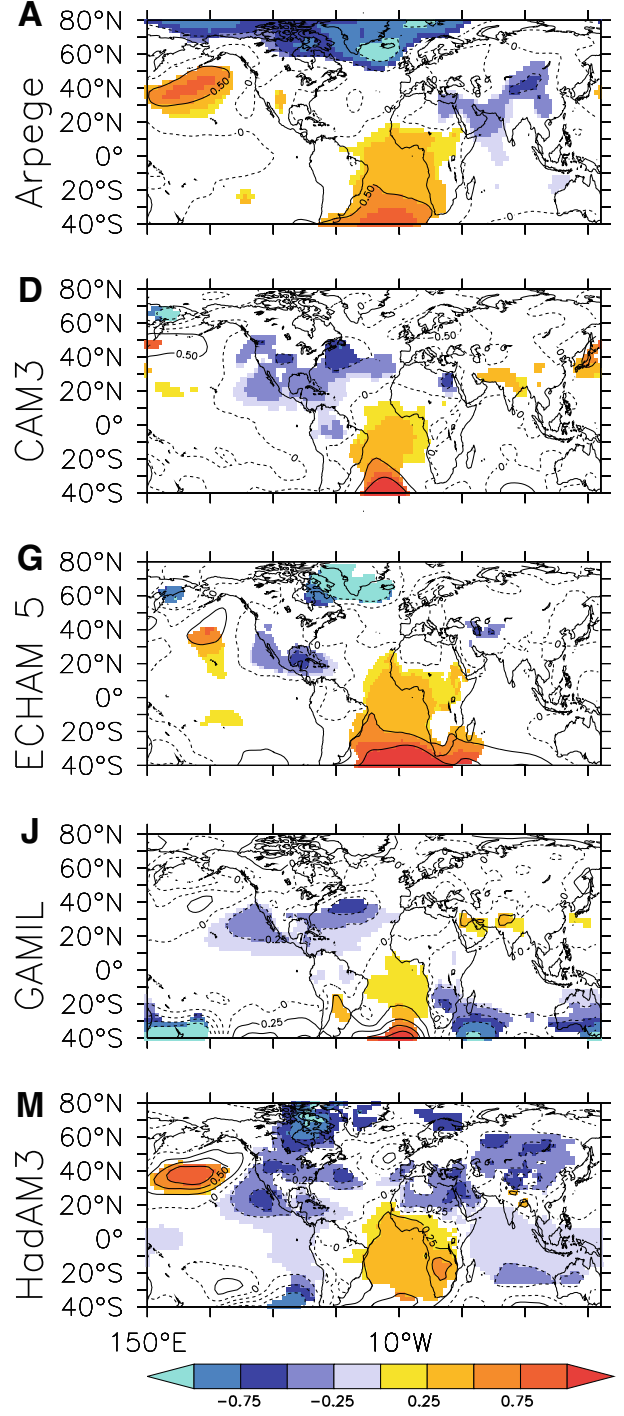

B

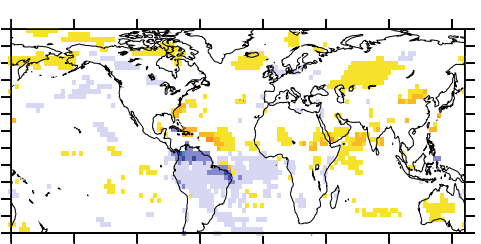

$\mathbf{E}$

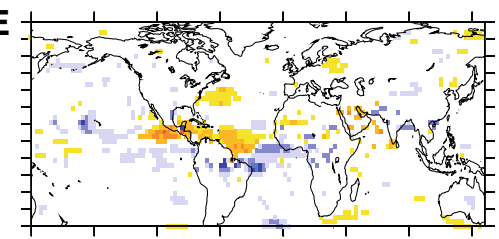

H
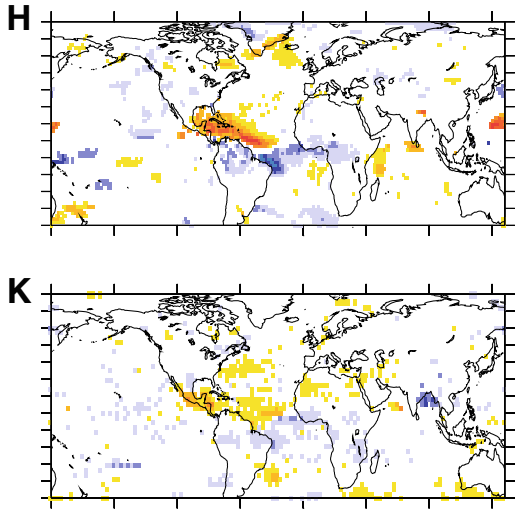

$\mathbf{N}$

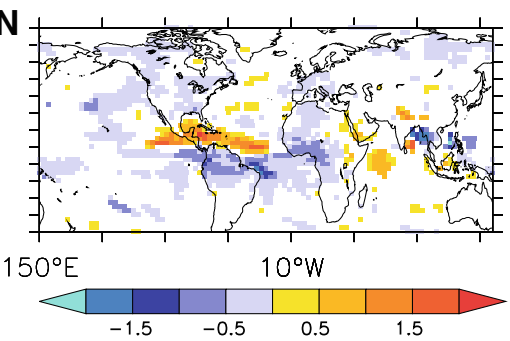

C
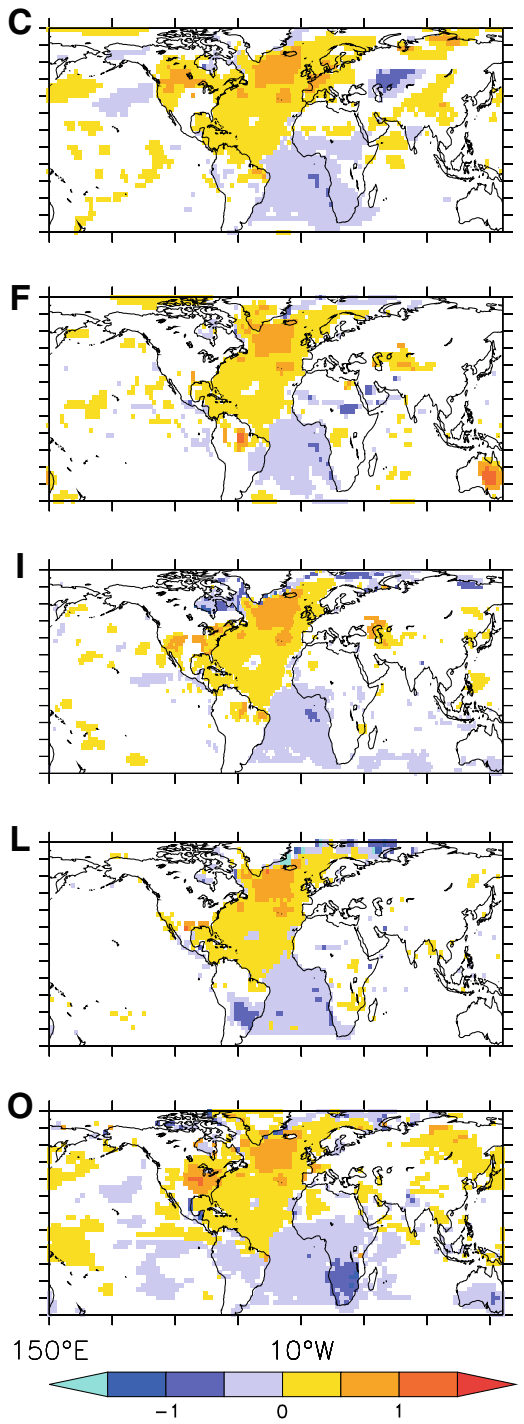

Fig. 3 JJA atmospheric response to warming of the North Atlantic (AP-CNTL). a Mean Sea Level Pressure in $\mathrm{hPa}, \mathbf{b}$ precipitation in $\mathrm{mm} /$ day, (c) surface air temperature in ${ }^{\circ} \mathrm{C}$ in Arpege. $(\mathbf{d}-\mathbf{f})$ as $(\mathbf{a}-\mathbf{c})$ but for CAM3. g-i Echam5. j-k GAMIL. m-o HadAM3. In all panels, regions where anomalies are not significant at the $95 \%$ level $(p>0.05)$ are shaded white 
the western Atlantic, across the US to the eastern Pacific in all models, except Arpege. This low pressure signature is similar to that seen in Summer (JJA) in Sutton and Hodson (2005), and is characteristic of a Gill-type response to offequatorial heating (Gill 1980), see also Wang et al. (2007); note there will be anomalous latent heating associated with the anomalous precipitation). A measure of this response (Fig. 4a) shows that all models (except Arpege) have similar North American MSLP responses to the North Atlantic SSTs, which are comparable to the response seen by Sutton and Hodson (2005). Examining the upper level stream function (Fig. 5) reveals that all models (except Arpege) have an significant anomalous anticyclone above the negative US MSLP anomaly. Such an anticyclone is characteristic of a Gill-type response to off-equatorial heating and hence suggests that the US MSLP anomaly is a Gill-type response to the diabatic forcing within the Caribbean region (see also Wang et al. 2007, 2008).

Additionally, CAM3, Echam5, GAMIL and HadAM3 show divergent outflow in the $200 \mathrm{hPa}$ velocity potential over the Caribbean (Fig. 5)—consistent with diabatic heating and ascent caused by the precipitation anomalies seen in the region. Arpege however, shows almost entirely the opposite behaviour - a large anomalous inflow, and hence region of descent, over northern South America. Examining Fig. $3 b$ reveals that Arpege produces a rainfall anomaly over Northern S. America (e.g. Colombia, Venezuela and Guyana) of between -1.0 and $-0.5 \mathrm{~mm} /$ day. This anomaly is
Fig. 4 a MSLP response (AP-CNTL) over the US (130W:70W, $15 \mathrm{~N}: 45 \mathrm{~N}$ ) in JJA for all models divided by the difference between the SST fields used to force the experiments, averaged over the box $100 \mathrm{~W}: 10 \mathrm{~W}, 0: 30 \mathrm{~N}$ (excluding a small number of negative gridpoints). The error bars show one standard error in the mean, computed from each model ensemble. (b) as (a) but for precipitation response over land over the US (130W:70W, $27 \mathrm{~N}: 45 \mathrm{~N})$. (c) as (b) but for surface air temperature. SUT05 are rescaled results from a similar but more idealised experiment with HadAM3 described in Sutton and Hodson (2005). (There is an implicit assumption of linearity in this scaling.)
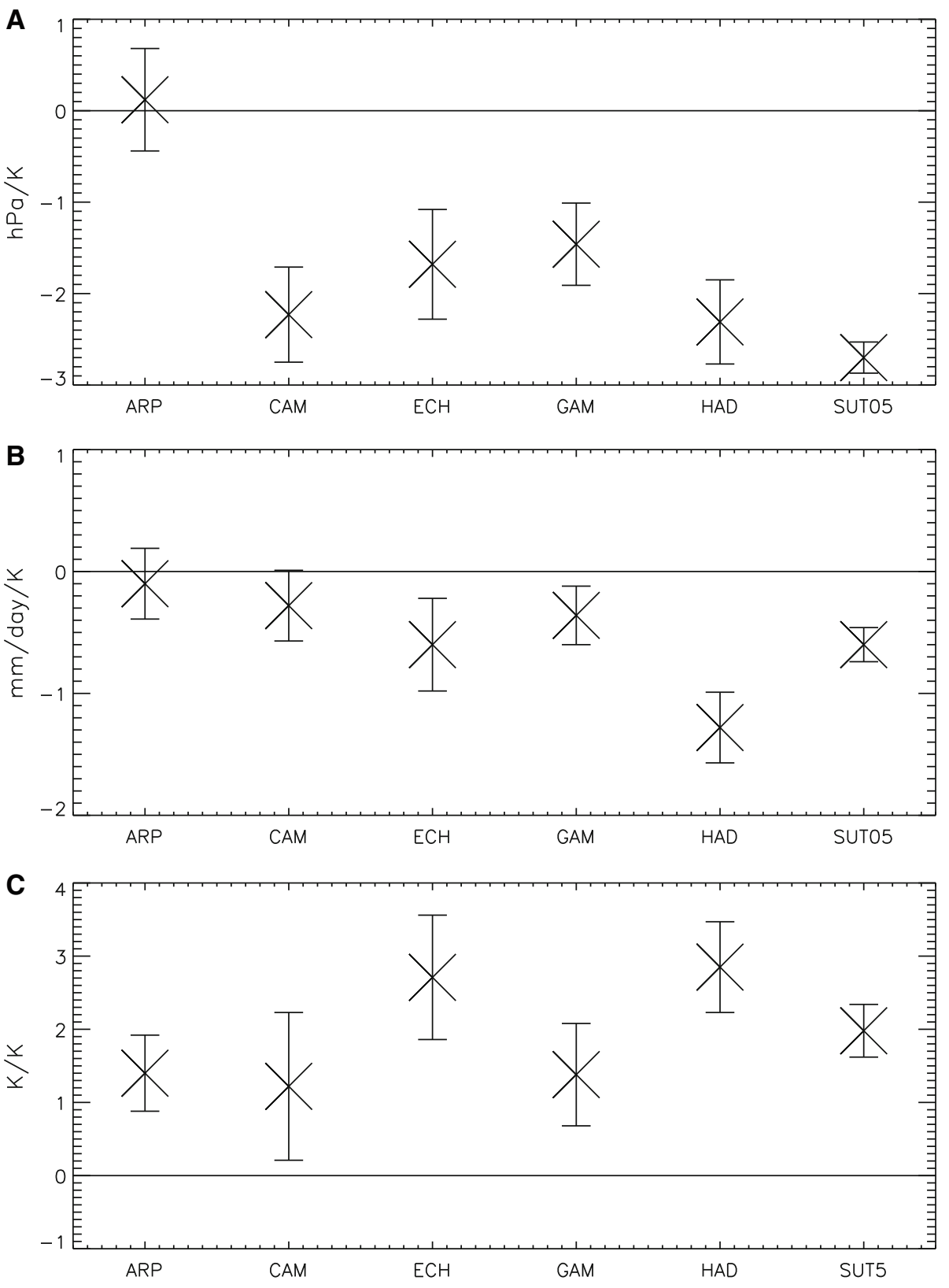
significant and notably larger than any other model produces in this region during JJA. The co-location of the rainfall and velocity potential anomalies suggests that Arpege is responding to the significant negative precipitation anomaly in this region. This descent may, in part, be responsible for the suppression of precipitation anomalies within the Caribbean region. The differences seen in the Arpege results will be discussed further in Sect. 5 .

All models show a clear cross-equator dipole in precipitation over the tropical Atlantic. Such a local response to the cross-equator dipole in the underlying SST forcing pattern is well known from other model studies (e.g. Folland et al. 2001; Okumura et al. 2001; Moura and Shukla 1981) and is consistent with analysis of observations (Zhou and Lau 2001; Uvo et al. 1998). The dipole extends westwards over land, with reduced precipitation over Brazil and northern South America, and north westwards with increased precipitation over the Caribbean. Over North America, only HadAM3 shows significant regions of reduced precipitation (comparable to the changes found by Sutton and Hodson (2005)). This response is scarcely significant in the other models. Precipitation averaged over the whole of North America (Fig. 4b) shows reductions in all models, although only HadAM3 and SUT05 are significantly $(p<0.05)$ different from zero. The response of HadAM3 is over three times the mean of the other four models and twice that of Echam5. This occurs despite the common SST forcing. The stronger response of HadAM3 will be discussed in Sect. 5 .

In South America, there are reductions in precipitation over Colombia, Venezuela and parts of Brazil. The magnitude of the response varies considerably between models, with the strongest impacts seen in Arpege and HadAM3 $(-0.31$ and $-0.34 \mathrm{~mm} /$ day respectively, over the region $(50 \mathrm{~W}: 80 \mathrm{~W}, 20 \mathrm{~S}: 5 \mathrm{~N})$ ) and the weakest seen in GAMIL $(-0.05 \mathrm{~mm} /$ day $)$. This impact extends across the tropical Atlantic resulting in reduced rainfall over western equatorial Africa in some models. The strongest response is seen in HadAM3 with reductions of up to $1 \mathrm{~mm}$ /day over Nigeria, Ghana and Ivory Coast. Models which do not show a strong response in this region (Arpege, CAM3, GAMIL) show a weak increase in rainfall $(<0.5 \mathrm{~mm} /$ day $)$ over the Sahel and Sahara.

Over North America all models show some warming (Figs. 3, 4), although the warming in CAM3 and GAMIL is not significantly different from zero. The strongest warming is seen in HadAM3; with a similar spatial pattern to that seen in Sutton and Hodson (2005). There is very little consistency between the modelled temperature responses elsewhere, except for the increased temperatures along the north east coast of South America (likely to be linked, through changes in cloud cover, to the co-located reductions in precipitation).

\subsection{Boreal winter}

The response of the models in Boreal Winter (DJF) (Fig. 6) is generally weaker than that in Boreal Summer. Again, all models show cross-equator dipoles in both MSLP and precipitation over the tropical Atlantic. The precipitation dipole is further south in this season resulting in increased precipitation over northern South America in most models and reduced precipitation over Nordeste Brazil.

Responses over the Aleutian low region in the North Pacific (40N) are also seen in this season, with significant responses seen in GAMIL and HadAM3-suggesting a possible Atlantic-Pacific teleconnection (a similar, but weaker, response is also seen in some models during Boreal Summer (JJA, Fig. 3). This result is consistent with a recent study by Okumura et al. (2008) which demonstrates that rapid changes in the Atlantic MOC, leading to a cooling of the North Atlantic Ocean, can result in a deepening of the Aleutian Low.

There are very few common significant temperature responses between the models in this season. A notable exception is the very eastern edge of Nordeste Brazil which sees a slight warming in all models-this is, as in boreal summer, likely due to increased insolation in this region as a result of reductions in the modelled cloud cover.

Overall the extratropical response to the Atlantic SST warming pattern is generally weak and inconsistent between the models in this season. Notably, there is no clear response of the North Atlantic Oscillation (NAO). Previous results (Sutton and Hodson 2003) have suggested that low frequency variations in North Atlantic SST may have forced decadal changes in the NAO. However, those results were derived from experiments using an atmosphere model forced with global observed SSTs, in contrast to the experiments presented here. One possible hypothesis for these contrasting results is that the NAO may only respond to decadal variability in Atlantic SSTs in the presence of specific SST variations outside the Atlantic basin.

\section{Comparison with observations}

As described above the Atlantic SST anomalies for the warm Atlantic experiment (AP) were derived from observational data from 1951 to 1960 whilst the SST forcing field for the control experiment (CNTL) was derived from observational data from 1961 to 1990 . Figure 7 shows the observed changes in MSLP, precipitation and surface temperature which occurred between these two periods. As mentioned in Sect. 2.3, it is likely that, between 1951 and 1990, many factors influenced the evolution of the atmosphere besides changes in the Atlantic Ocean: changes in other ocean basins (e.g. the Indian Ocean), increasing 

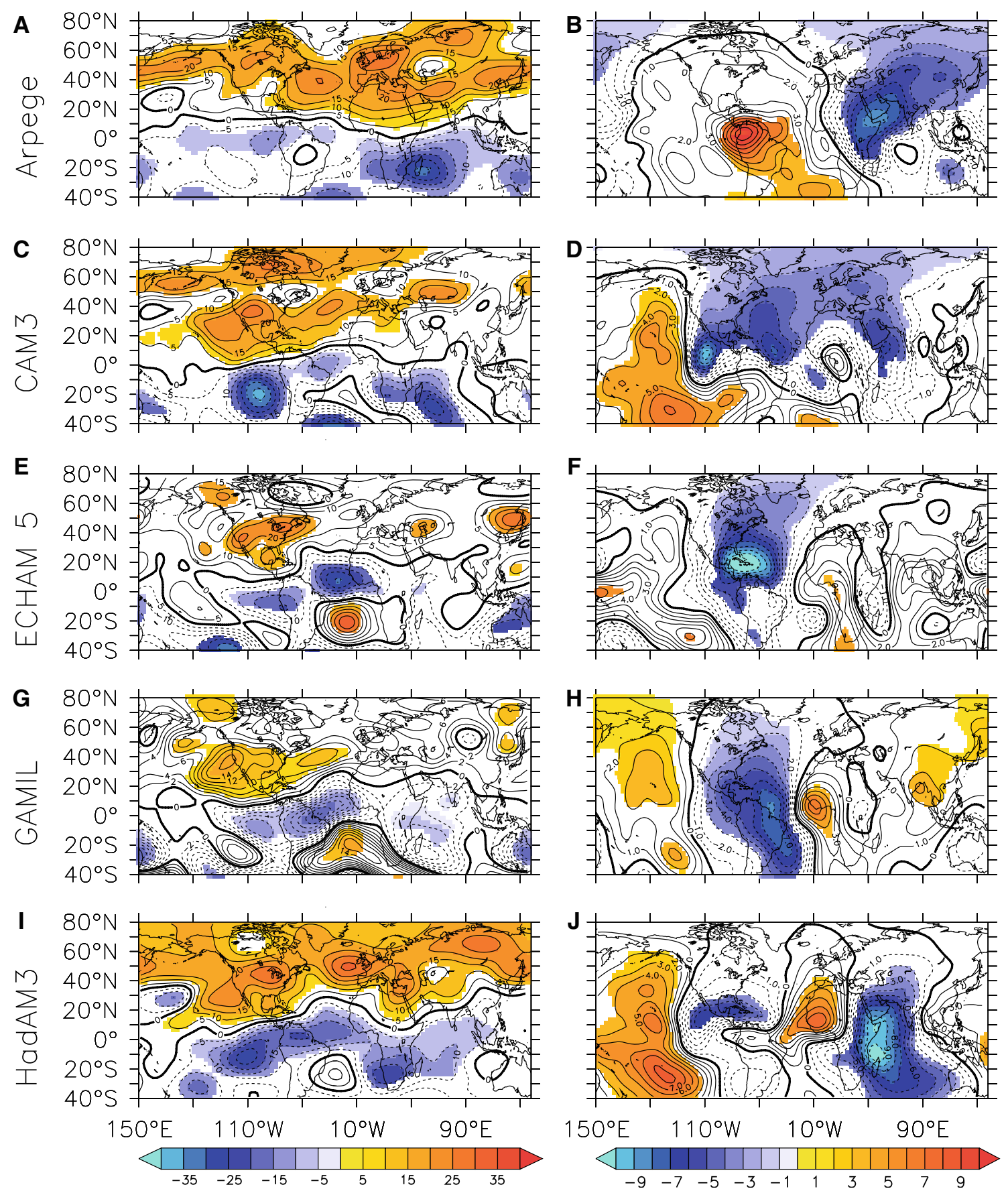

Fig. 5 Left column JJA $200 \mathrm{hPa}$ stream function $(\psi)$ response to warming of the North Atlantic (AP-CNTL). Contour interval is $5 \times 10^{5} \mathrm{~m}^{2} \mathrm{~s}^{-1}$. Right column JJA $200 \mathrm{hPa}$ velocity potential $(\phi)$

levels of green house gases, varying concentrations of aerosols and so on. We therefore expect there to be significant differences between the model results and observations. However, where there are similarities, we can begin to attribute the observed changes to the effect of the observed changes in Atlantic SSTs over that period.

During Boreal Summer (JJA), the observational composite (Fig. 7a) shows a similar low pressure anomaly over response to warming of the North Atlantic (AP-CNTL). Contour interval is $10^{5} \mathrm{~m}^{2} \mathrm{~s}^{-1}$. Shading as Fig. 3. Note: $u=-\frac{\partial \psi}{\partial y}+$ $\frac{\partial \phi}{\partial x}, \quad v=\frac{\partial \psi}{\partial x}+\frac{\partial \phi}{\partial y}$

the North Atlantic and North America to that seen in the model results (Fig. 3) (except for Arpege). There is also some consistency between the observed temperature anomalies over North America (Fig. 7c) and the model results for Echam5, HadAM3 and possibly GAMIL (Figs. 3i, o, 1). Observed precipitation anomalies over North America in JJA (Fig. 7b) are weak, but are consistent with the model results (Fig. 3). 
Elsewhere there is less consistency. The observed positive MSLP anomaly seen over Greenland (Fig. 7a) is not captured by the models, indeed Arpege, HadAM3 and Echam5 all display the opposite sign over the region. The changes in Sahel precipitation, clearly seen in the observations (Fig. 7b) are also not seen in the model results. This suggests that the observed decreases in Sahel precipitation over the latter half of the twentieth century were not a result of the observed interhemispheric Atlantic SST contrast (Fig. 2) and that some other factor was responsible. This is in disagreement with some modelling studies (e.g. Hoerling et al. 2006), which suggests that the interhemispheric contrast was a major factor in recent Sahel precipitation changes. However, studies examining the influence of the Indian ocean (e.g. Bader and Latif 2003; Giannini et al. 2003) suggest that the anomalies in the Indian ocean (such as those seen in Fig. 2) may also have played a significant role. Zhou et al. (2008) suggested that the decreasing tendency of Sahel precipitation, which is a local manifestation of global land monsoon precipitation change, was mainly caused by the warming trend over the central-eastern Pacific and the western tropical Indian Ocean.

In Boreal Winter (DJF) the negative MSLP anomaly off the North-East coast of South America (Fig. 7d) is captured by all the models (Fig. 6), to varying degrees. The southern positive lobe of the MSLP dipole seen in all the models, is by contrast not seen in the observations. (However, observational data is known to be sparse, and hence perhaps unreliable, in this region).

Over the Aleutian Low system at $40 \mathrm{~N}$, the positive MSLP signal seen in HadAM3 and GAMIL (Figs. 6j, m) is also seen in the observational composite (Fig. 7d) and Atlantic MOC adjustment experiments (Okumura et al.
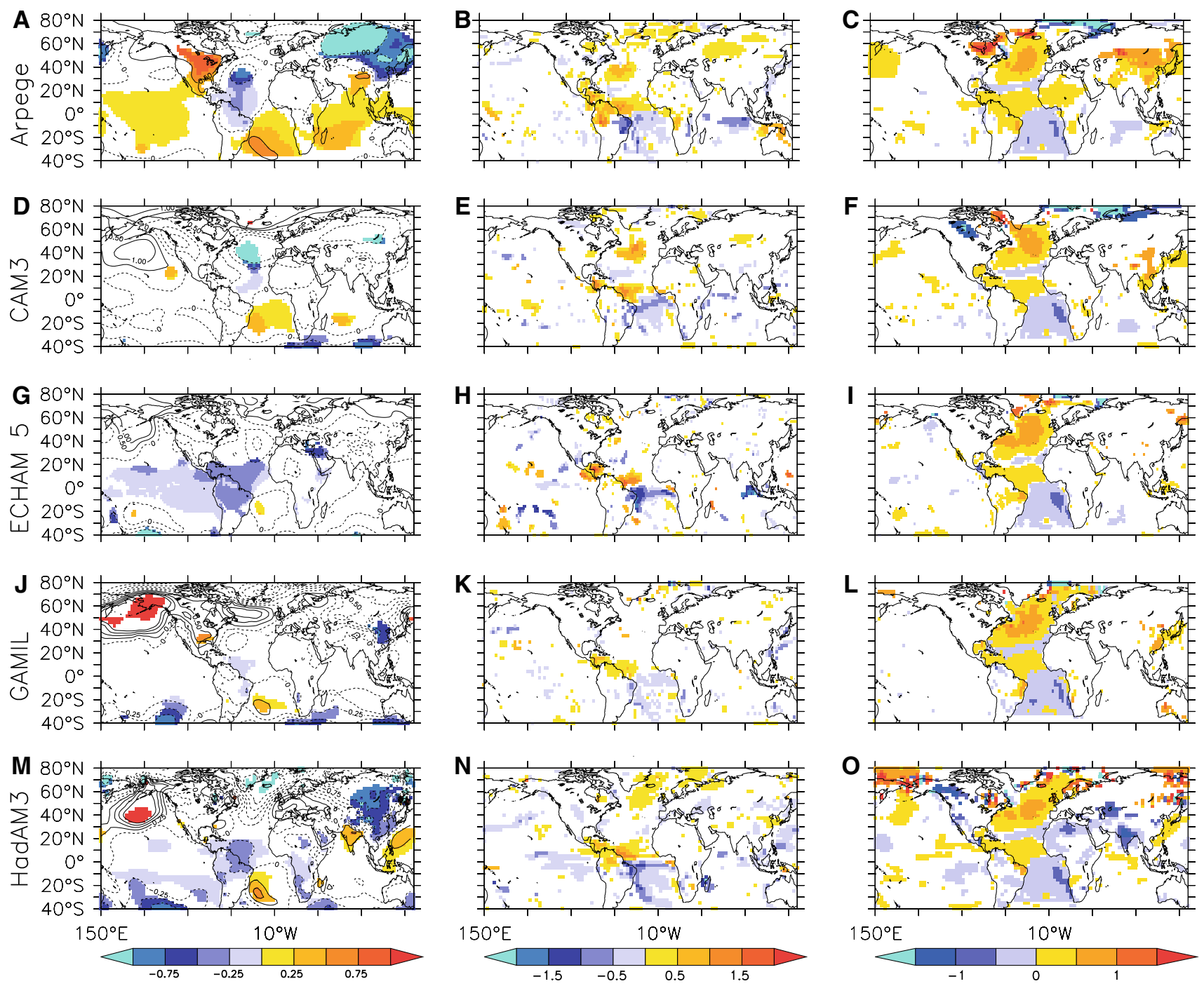

Fig. 6 DJF Atmospheric response to warming of the North Atlantic (AP-CNTL). As Fig. 3, but for boreal winter (DJF) 


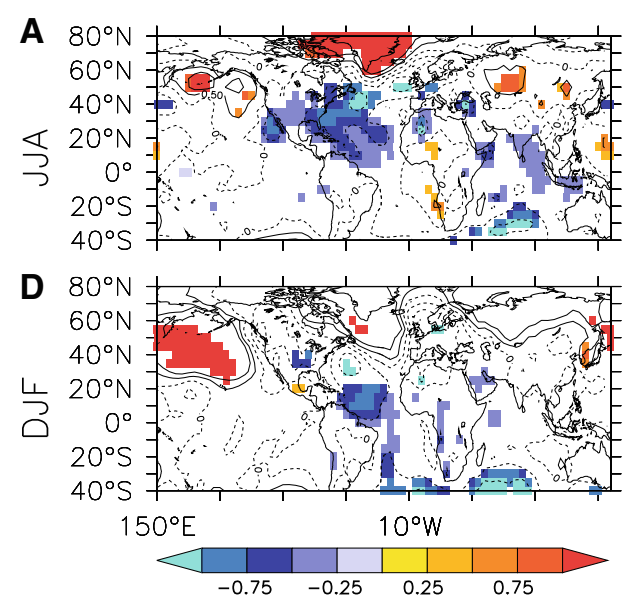

Fig. 7 Observed changes in climate between 1951:1960 and 1961:1990. a JJA MSLP difference between the mean of 1951 to 1960 minus the mean of 1961 to 1990 . Units are hPa. Contour interval

2008). This agreement may suggest that observed changes in the Aleutian low may owe their origin, at least in part, to changes in Atlantic SSTs.

There is little consistency between the modelled surface air temperatures (Fig. 6) and observations (Fig. 7f) in DJF. Even the strong positive anomalies seen in observations over eastern North America are not captured by any model in this season, suggesting that decadal variations in Atlantic SST were not influential in determining these changes.

\section{Discussion}

The results in Sect. 3 demonstrate that the greatest impacts of the warm Atlantic SST anomalies are seen over the Americas. We now examine in greater detail the differences between the models, including the seasonal evolution of the impacts, in this region.

\subsection{Comparison of responses over North America}

\subsubsection{Impact of increased model resolution for Arpege}

Alongside model parameterisations and choice of dynamical schemes, model resolution is an important factor that may contribute towards the different responses of different models to a common forcing. Previous studies have documented systematic changes resulting from increasing model resolution. For example, Navarra et al. (2008) demonstrated that increased atmospheric resolution resulted in a reduction in some systematic mean state errors in the SINTEX-F model. Roeckner et al. (2004) demonstrated that changes in horizontal and vertical atmospheric resolution resulted in significant changes in the mean state, e.g. the strength of the Hadley circulation, within Echam5.

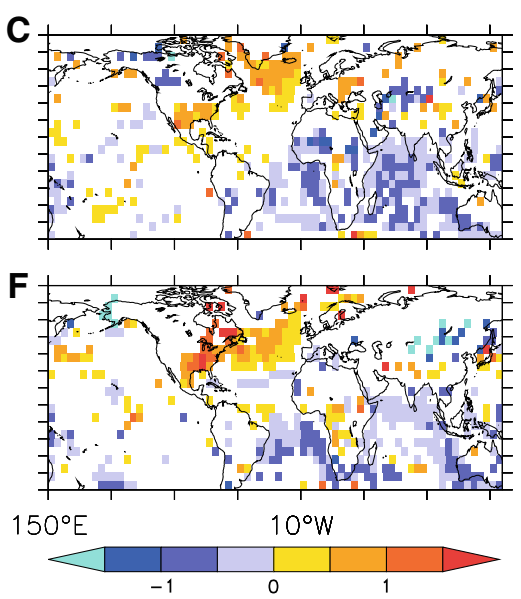

is $0.5 \mathrm{hPa}$. (b) as (a) but for rainfall rate. Units are $\mathrm{mm} / \mathrm{day}$. (c) as (a) but for surface air temperature. Units are $\mathrm{K}$. $(\mathbf{d}-\mathbf{f})$ as $(\mathbf{a}-\mathbf{c})$, but for DJF. Shaded regions are significant at the $90 \%$ level $(p<0.10)$

In order to examine the sensitivity of the Arpege response to model resolution, an additional set of experiments was completed with an increased resolution version of Arpege. This second set of experiments (ArpegeHIRES) used a version of Arpege with an increased resolution (up to T397) over the North Atlantic Ocean and reduced resolution over the southern Hemisphere (resulting in an average global truncation of T159).

In boreal summer (JJA), Arpege-HIRES shows a similar MSLP response (Fig. 8a) to that seen in the other four models (Fig. 3). The significantly increased Caribbean rainfall (Fig. 8c) (in contrast to Arpege-Fig. 3b) is a likely source of the latent heating required to drive the Gill-type MSLP response. Aside from these differences, Arpege-HIRES generally responds in a similar manner to Arpege in both boreal summer and winter. We therefore conclude that model resolution can be an important factor in determining certain aspects of the response of North American summer climate to changes in North Atlantic SSTs. We examine the differences between these two models in more detail in the following sections.

\subsubsection{Seasonal evolution of the response}

To further analyse the model differences over North America, we now examine the seasonal evolution of each response averaged over North America (Fig. 9). For all models, the strongest MSLP response (a negative anomaly) over North America is seen between July and October (Fig. 9a), with most models reaching a minimum between August and October. Most models also show an earlier, weaker minimum between April and June. Between April and October these responses are generally stronger, but of the same sign, as observations. The lack of a low pressure anomaly in JJA in Arpege (Fig. 3a) is clearly due to a very 
A

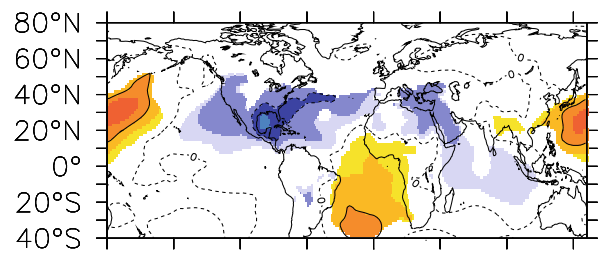

D

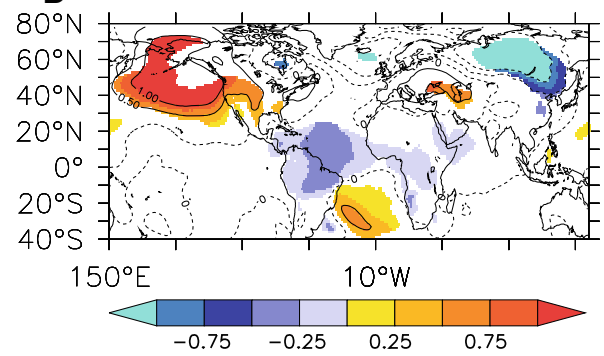

B

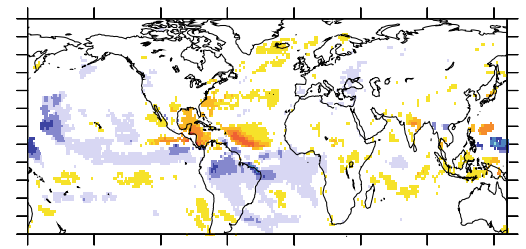

E

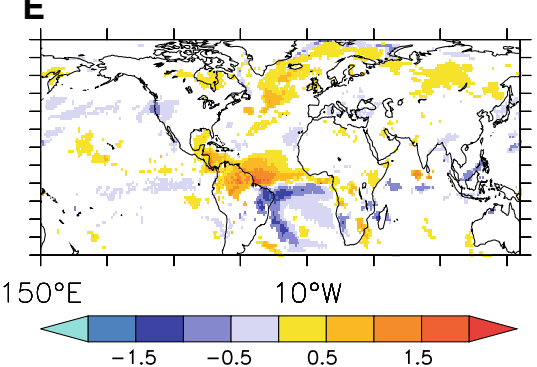

C

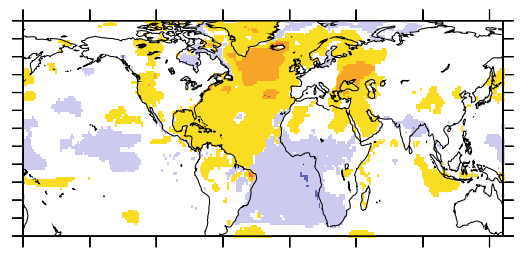

$\mathbf{F}$

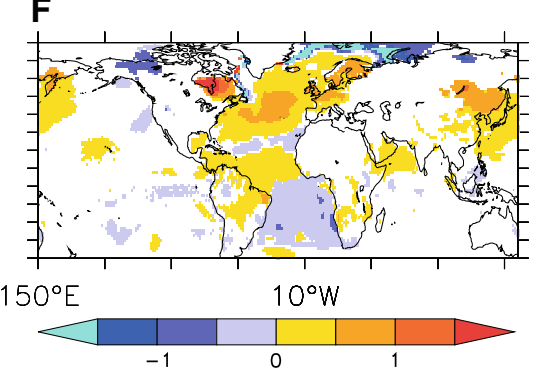

Fig. 8 High resolution Arpege atmospheric response to warming of the Atlantic (AP-CNTL) in JJA for a Mean Sea Level Pressure in hPa, b precipitation in $\mathrm{mm} /$ day, $\mathbf{c}$ surface air temperature in ${ }^{\circ} \mathrm{C}$. using a high resolution version of Arpege. (d-f) as (a-c) but for DJF. Shading as Fig. 3

weak model response during JJA (not significantly different from zero), rather than an unresponsiveness of Arpege to the SST forcing anomaly throughout the entire year.

All models show a significant warming over North America (Fig. 9b) during JJA consistent with the observed warming between the two periods. The results outside of boreal summer are less consistent and in most cases not significantly different from zero.

Out of all of the models, only HadAM3 demonstrates a significant reduction in rainfall across North America throughout the summer and beyond (indeed from April to October). All other models, and observations, show no significant change in rainfall on the monthly timescale. Arpege-HIRES is a notable exception, as it shows a significant increase in rainfall during August (also seen in 8b). From this analysis we conclude that the models have broadly consistent MSLP and Surface Temperature responses to a warming of the North Atlantic SSTs, a warming during the summer months and a reduction in MSLP during the late summer and early autumn, but that the majority of models show no response in summer rainfall.

\subsubsection{MSLP connection to Caribbean rainfall}

The summer MSLP response over North America is characteristic of a Gill-type response to off-equatorial heating. As discussed in Sect. 3.1, a likely source of this heating is the increased rainfall over the Caribbean region. Figure 10 demonstrates that the modelled Caribbean rainfall generally responds to the seasonal variations in local SST - with increased rainfall at times when the underlying SSTs are warmest (with the notable exception of Echam5).
Comparison with Fig. 9a shows that the largest MSLP anomalies generally occur over North America when the largest rainfall anomalies occur over the Caribbean. Table 1 shows the correlation between the MSLP index in Fig. 9a and the PPT Index in Fig. 10a, for each model. All models show an anti-correlation between US MSLP and Caribbean PPT across the year (although only Arpege, HadAM 3 and CAM3 are statistically significant $(p<0.05))$. These correlation supports the hypothesis that the North American MSLP pattern is a response to latent heating from Caribbean rainfall.

Arpege demonstrates the largest amplitude variations over the seasonal cycle, with maxima in May and September and a minimum between June and August. This latter minimum in summer rainfall, and hence latent heating, explains the lack of response seen in JJA in Figs. 9a and 3a. Arpege-HIRES in turn responds in a manner more similar to that of HadAM3, CAM3 and GAMIL, with significant rainfall anomalies during the summer months.

The climatological rainfall over the Caribbean during JJA is greater in both Arpege models than either the observed climate or the other models (Fig. 10b). The summertime peak in Caribbean climatological rainfall ${ }^{2}$ (July for Arpege, June for Arpege-HIRES) coincides with the summertime minimum in anomalous Caribbean rainfall (Fig. 10a). This co-incidence suggests that these minima may result from a saturation of the local precipitation response which is not seen in the other models.

\footnotetext{
2 The rainfall mid-summer minimum, or Mid Summer Drought (MSD), is thought to be a consequence of a westward extension of the North Atlantic Subtropical High (NASH) pressure system over the Caribbean region (Curtis and Gamble 2008; Gamble et al. 2008).
} 
Fig. 9 Indices of anomalous (AP-CNTL) monthly mean a Mean Sea Level Pressure averaged over the North American box (70W:130W, $15 \mathrm{~N}: 45 \mathrm{~N}$ ) and b temperature and $\mathbf{c}$ precipitation-both averaged over land within the box (70W:130W, 27N:45N), for all models. Dashed lines are observed differences between (1951:1960) and (1961:1990). Starred points are those which are significantly different from zero $(p<0.05)$. The grey shading shows \pm 1 standard error $(=\sigma / \sqrt{n})$ for each model computed from the ensemble spread.
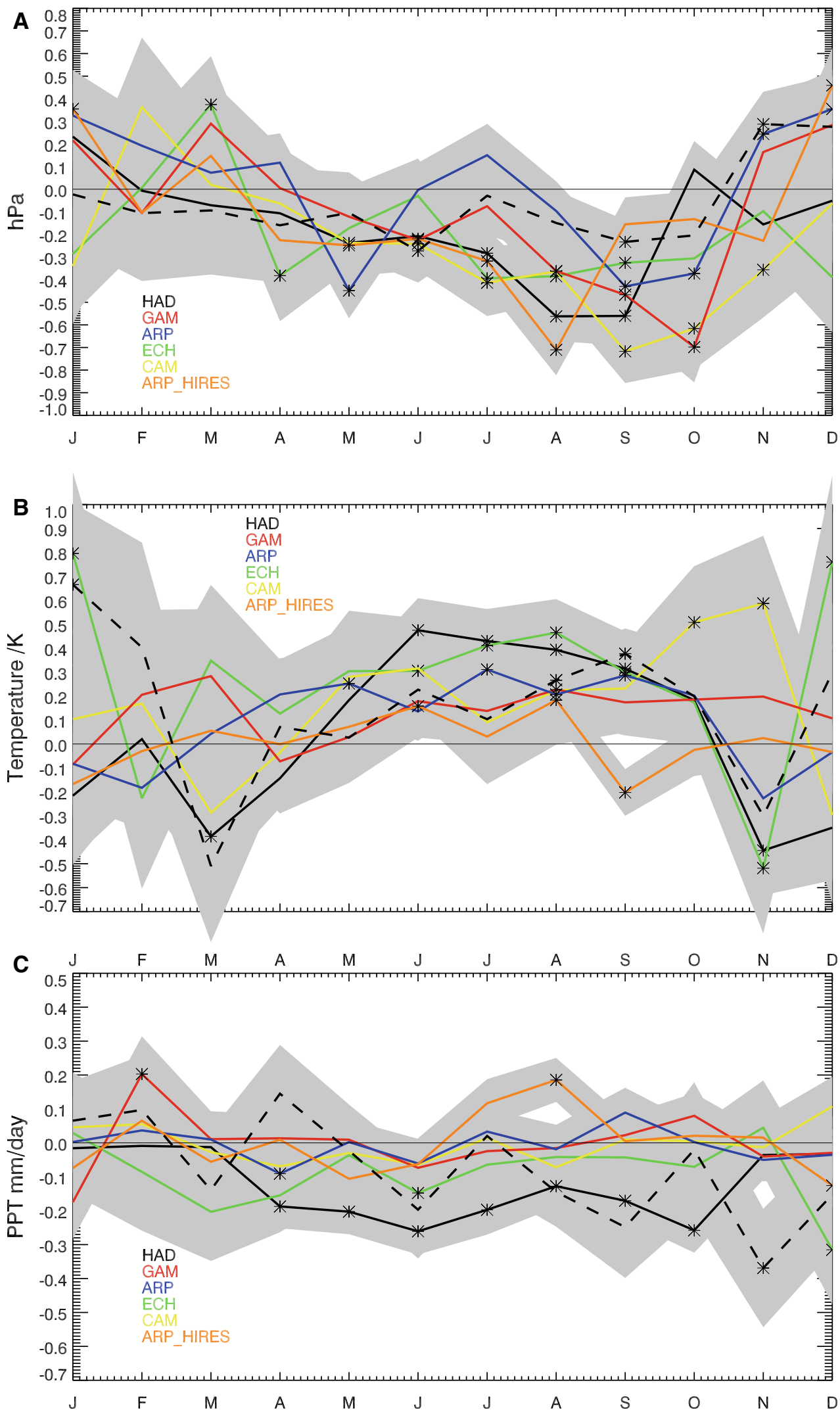
Fig. 10 a Indices of anomalous (AP-CNTL) monthly mean precipitation averaged over the Caribbean region $(60 \mathrm{~W}: 100 \mathrm{~W}$, 10:30N), for all models. Dashed line is the SST forcing pattern anomaly averaged over the same box. b Monthly evolution of precipitation in the control for each model averaged over the Caribbean region. Dashed line is the observed precipitation climatology (1961-1990) averaged over the same box. Shading and starring as Fig. 9
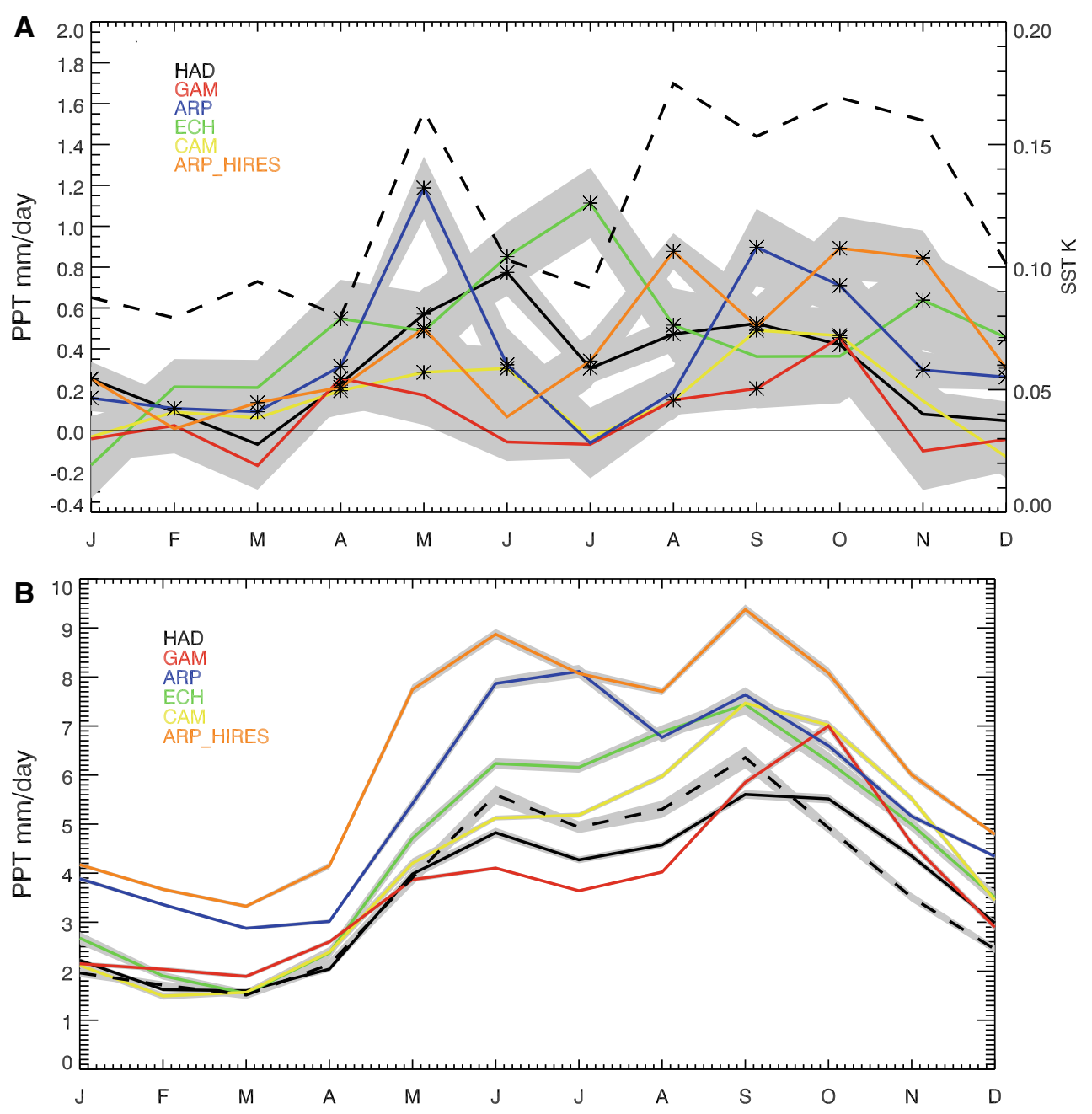

Table 1 Correlations between index of US MSLP shown in Fig. 9 and Caribbean PPT shown in Fig. 10 for all models

\begin{tabular}{lccccc}
\hline Model & Arpege & CAM3 & Echam5 & GAMIL & HadAM3 \\
\hline Correlation & $\mathbf{- 0 . 8 5}$ & $\mathbf{- 0 . 6 9}$ & -0.22 & -0.46 & $\mathbf{- 0 . 5 9}$ \\
\hline
\end{tabular}

Correlations in bold are statistically significant $(p<0.05)$

Additionally, the descent seen over South America in Arpege (figure 5b) may contribute to a suppression of rainfall within the Caribbean region. This suggests that there may be competition between the two regions; a balance between enhanced Caribbean ascent due to positive North Atlantic SST anomalies, and enhanced South American descent due to negative South Atlantic SST anomalies.

\subsubsection{Anomalous rainfall over North America in HadAM3}

The summer rainfall $(P)$ in HadAM3 (Fig. 9c) can be separated into contributions from evaporation $(E)$ and moisture convergence $(-\nabla \cdot \mathbf{Q})$ according to the approximate relationship, $P \approx E-\nabla \cdot \mathbf{Q}$ (Peixoto and Oort 1993), where the moisture flux $\mathbf{Q}$ is given by $\mathbf{Q}=\mathrm{q} \mathbf{v}$ ( $q$ is the specific humidity and $\mathbf{v}$ the wind field). Figure $11 \mathrm{a}-\mathrm{c}$ shows this decomposition for HadAM3 CNTL during JJA. Evaporation is balanced by moisture divergence over large parts of the ocean and some regions over land. Regions of intense rainfall are generally associated with regions of high moisture convergence (e.g. the ITCZ) rather than regions of high evaporation. The rainfall anomaly over North America (Fig. 11d), on the other hand, is clearly associated with reduced evaporation (Fig. 11e), rather than changes in moisture flux convergence (Fig. 11f). Hence the changes in rainfall seen in HadAM3 are a consequence of a local reduction in the precipitation-evaporation balance. Further analysis of HadAM3 reveals a significant $(p<0.05)$ anomalous temperature inversion (AP-CNTL) at $850 \mathrm{hPa}$ over the region (not shown); this inversion is not seen in the other models. This analysis suggests that the local change in the P-E balance may arise as a consequence of a reduction in moist convection, and hence rainfall, within the region due to the enhanced static stability 
A

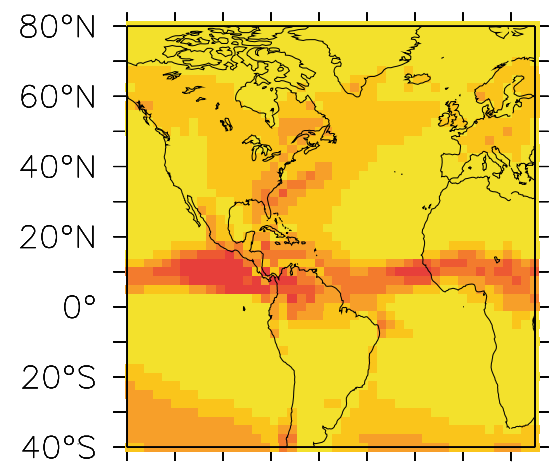

D

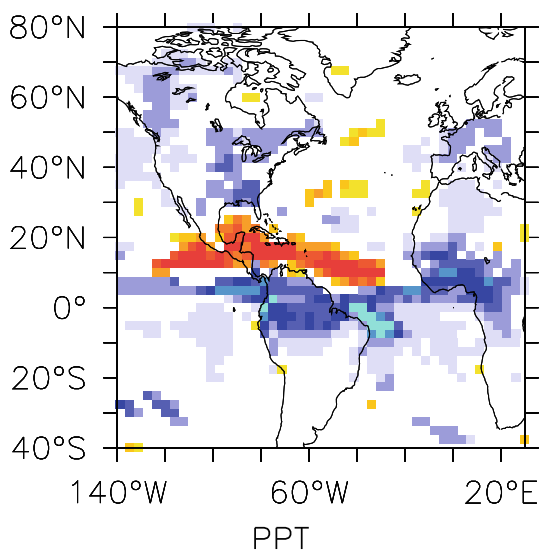

B

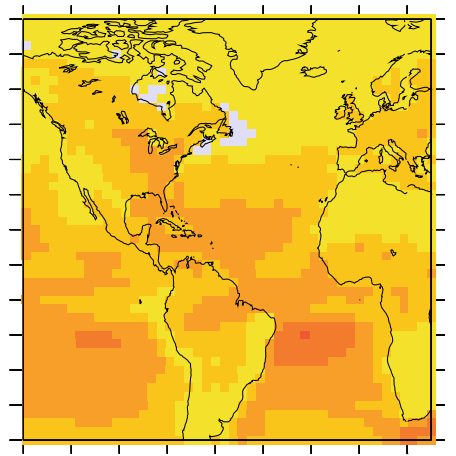

E

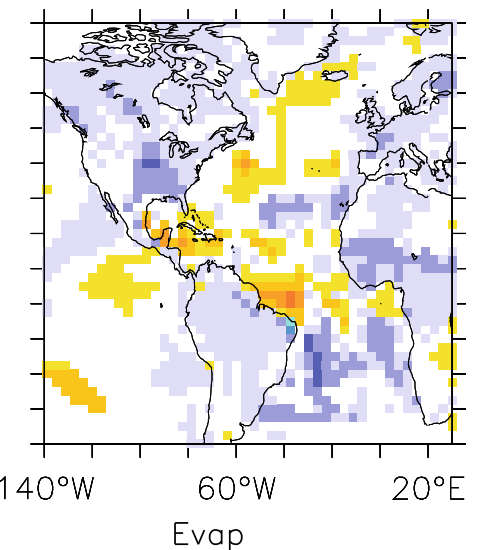

C

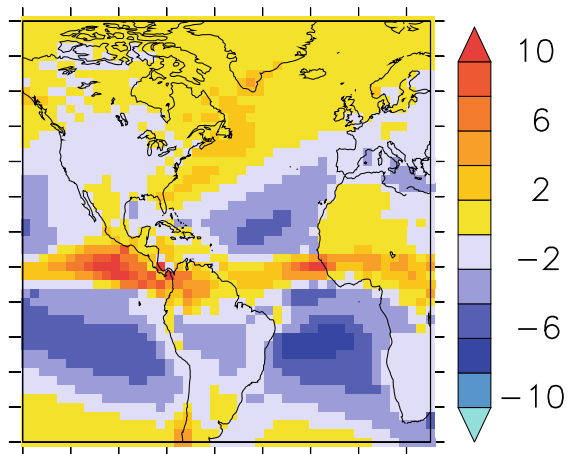

F

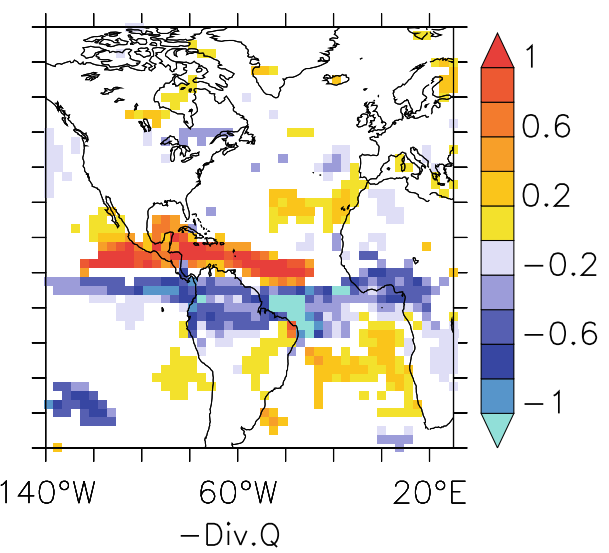

Fig. 11 a JJA precipitation (mm/day) in HadAM3 CNTL. b JJA evaporation (mm/day) in HadAM3 CNTL. c Difference between (a) and $(\mathbf{b}) \approx-\nabla \cdot \mathbf{Q}$, where $\mathbf{Q}$ is the vertically integrated moisture flux. $\mathbf{d}-\mathbf{f}$ as a-c except for AP-CNTL. Shading in (d-f) as Fig. Fig. 3

associated with the anomalous temperature inversion. Changes in soil moisture may also be influential, however. Analysis of HadAM3 reveals significant negative soil moisture anomalies (AP-CNTL) in this region during summer (not shown). These anomalies may arise as a consequence of a recently discovered minor bias in the HadAM3 soil model (P. L. Vidale, 2008, personal communication). This bias results in an overly sensitive soil model which evaporates moisture into the atmosphere too easily. If the soil initially dries rapidly by this mechanism it would reduced the moisture available to the local p-e balance for the remainder of the experiment.

In contrast to the reduced rainfall seen in HadAM3, a recent study by Wang et al. (2007) suggests that the climatological warm summer Caribbean SSTs in the Atlantic Warm Pool (AWP) drive significant moisture transport from the Gulf of Mexico to North America and enhanced summer rainfall. The resulting moisture transport is influenced by a balance between a suppression of the Great Plains Low Level Jet, which flows from the Gulf of Mexico, over North America, and enhanced evaporation over the Gulf of Mexico. However, Wang et al. (2008) demonstrate that this balance is not maintained on the multidecadal timescale where the smaller multidecadal SST anomalies result in both a weakened jet (which is not compensated for by an increase in evaporation) and reduced North American rainfall. These findings suggest that the impact on rainfall over North America may be sensitive to both the magnitude and spatial extent of the SST anomaly imposed in the Atlantic.

\subsubsection{Sensitivity to Atlantic warming pattern}

The results for HadAM3 within this study display a generally similar pattern to those previously detailed in Sutton and Hodson (2007) with a similar pattern of the response during boreal summer for Northern Hemisphere MSLP, rainfall and surface Temperature. (Unsurprisingly, given the changes in S. Atlantic forcing, the Southern Hemisphere results are less similar).

Over North America, the reductions in Summertime US rainfall described in Sutton and Hodson (2007) extend across almost the entire continental US. This contrasts to the results presented here, where the rainfall reductions are confined to the eastern half of the US. The difference in the extent of this response may suggest a non-linear response 
Fig. 12 a Difference in precipitation $(\mathrm{mm} /$ day) (AP-CNTL) averaged over the northern part of South America (50W:80W, 20S:5N) for the six models and observations (Dashed line, 1961:1990 1951:1960). b CNTL and observations (Dashed line, 1961:1990) over the same region. Shading and starring as Fig. 9
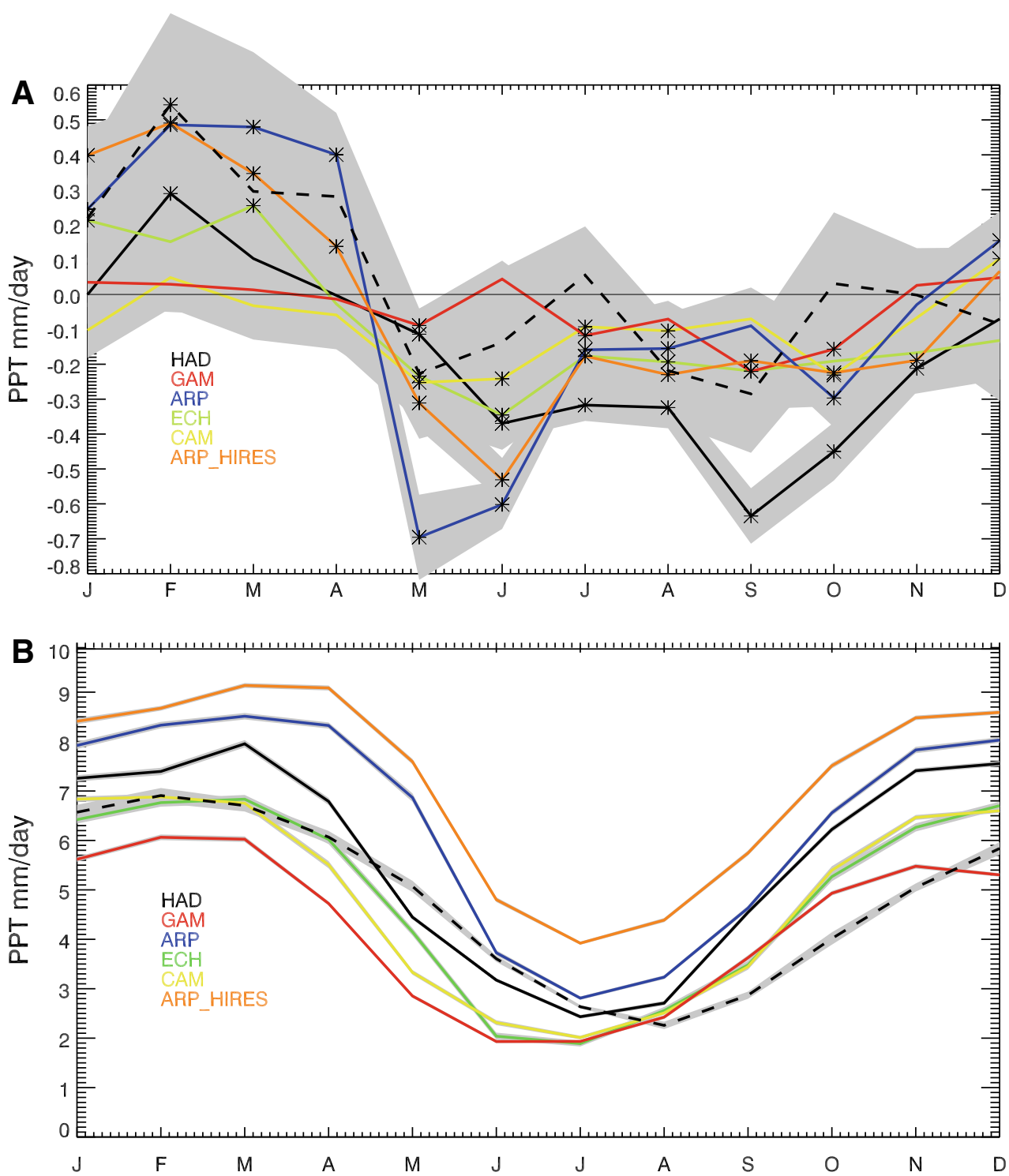

to the greater SST forcing applied in Sutton and Hodson (2007). However, an analysis of the moisture budget in the Sutton and Hodson (2007) experiments (not shown) suggests a similar balance of processes (between anomalous precipitation and evaporation, with very little role for anomalous moisture convergence) to that found in the experiments described in this study. Overall therefore we can conclude that, for HadAM3 at least, the general pattern of the response is not highly sensitive to details of the SST/ SIF forcing pattern.

\subsection{Rainfall response over S. America}

Significant rainfall anomalies are also seen over northern parts of South America in both summer (Fig. 3) and winter (Fig. 6). Between models, however, there is large disagreement on the magnitude of these anomalies. HadAM3 and Arpege (and Arpege-HIRES) show consistent strong, large scale anomalies in both summer and winter, whilst the other models generally show a much weaker and inhomogeneous response over land.

Figure 12 shows the evolution of the rainfall anomalies over this region $(50 \mathrm{~W}: 80 \mathrm{~W}, 20 \mathrm{~S}: 5 \mathrm{~N})$ throughout the seasonal cycle. The greatest disagreement between models occurs between December and April, where the responses range from CAM3 and GAMIL, which show no significant response, ${ }^{3}$ to Arpege which displays an increased rainfall $\sim 7 \%$ of the winter mean climatology. Arpege (and Arpege-HIRES) appear to be closest to the observed rainfall anomalies during this period. Significant model differences

\footnotetext{
$\overline{3}$ Both CAM 3 and GAMIL share the same thermodynamical core, and both have hydrological cycles that appear weaker than the other models in this study.
} 
persist until June; from July onwards the majority of models (except HadAM3) agree more closely with each other and observations.

All models reproduce the basic shape of the seasonal cycle in the rainfall climatology well (Fig. 12), although the magnitudes vary between models. Here, Arpege and Arpege-HIRES appear to be too active compared to observations. The models, also appear to produce a minimum in climatological rainfall at least a month earlier than in observations.

The main contribution to this seasonal cycle arises from the latitudinal migration of the ITCZ-located over northern South America during boreal winter and subsequently moving northwards over the Caribbean during boreal summer. Errors in the magnitude and phase of the seasonal cycle in rainfall in the region are therefore likely to be caused by errors in the representation of the spatial extent and seasonal migration of the ITCZ. It is notable that whilst the pattern of tropical Atlantic rainfall anomalies clearly extends over land in Arpege, Arpege-HIRES and HadAM3 (Figs. 3, 6, 8) the extension is much weaker in the other models. This suggests that differences in representation of the land surface may be pivotal for understanding the impacts of Atlantic SST variations within the region. Such variations between models are important to understand if future climate projections of rainfall and vegetation, within the region, are to be properly evaluated. The importance of narrowing uncertainty in projections of rainfall over Amazonia was highlighted in a recent study by Cox et al. (2008).

\section{Conclusions}

We have carried out experiments to investigate the climate impacts of multidecadal changes in Atlantic SST. A major goal of this study was to examine model uncertainty, i.e. the extent to which different atmospheric GCMs simulate consistent impacts. Therefore, identical experiments were carried out with six different models (Arpege, ArpegeHIRES, CAM3, Echam5, GAMIL and HadAM3). The experiments were designed to explore the impact of the change between the North Atlantic warm period, 19511960, and the subsequent cool period, 1961-1990. These experiments extended previous work that used more idealised SST forcing fields (Sutton and Hodson 2005, 2007); in particular, we included seasonal variations in the SST anomalies, consistent changes in Sea Ice Fraction, and SST anomalies in the South (as well as the North) Atlantic.

The major findings are as follows:

- The strongest response seen in Sutton and Hodson (2007), that of the Summer (JJA) MSLP over the US, is reproduced in all models, except the low resolution version of Arpege. This response is consistent with a Gill-type response to anomalous precipitation over the Caribbean. The responses are weaker than seen in Sutton and Hodson (2007), in line with the weaker imposed SST anomalies. This suggests that the use of SST and SIF patterns which more accurately reflect observed changes, does not greatly affect the large scale pattern of this climate response-but does affect the magnitude of the response.

- More detailed analysis over the United States shows that the models agree quite well on the predicted impacts on US temperature and MSLP, displaying warmer temperatures and lower pressures in response to a warmer North Atlantic and cooler South Atlantic, especially in the summer months (JJA). These anomalies are also in line with observations. The timing of maxima in these fields is subject to some model variability, however. There is less agreement between the models for US rainfall: HadAM3 shows a reduction in rainfall throughout spring, summer and early autumn - consistent with our previous study, but other models show no overall impact on rainfall. The reduction in HadAM3 appears to be associated with the developments of an anomalous temperature inversion, which is not seen in the other models, but may also be related to a recently discovered over-sensitivity in the HadAM3 soil model (P. L. Vidale, 2008, personal communictation). This mechanism different from to Wang et al. (2008) who demonstrate that reduced US rainfall in CAM3 (when forced with a warmer Atlantic Warm Pool) arises from a reduction in northward moisture transport associated with a weakened Great Plains Low-level Jet.

- There are also significant impacts on rainfall over northern South America. A warmer North Atlantic and a cooler South Atlantic, hence a greater Atlantic cross equatorial SST gradient, results in reduced rainfall during summer, and increased rainfall during winter over northern South America. There are very large differences in the magnitude (but not the sign) of this response between models during winter. During summer, the responses are more consistent, but still show significant variation in magnitude. Such differences between the model responses over northern South America may be partly attributable to differences in land surface schemes between the models.

- Outside the Americas and the Equatorial Atlantic (and perhaps North Pacific), there are no significant responses that are consistent between models in either Summer or Winter. Specifically, the imposed Atlantic SST anomalies have no consistent significant impact on the NAO. 
These results support previous evidence that decadal variability in Atlantic SST can have significant impacts on climate. In order to understand and quantify this impact further, there is a need to account for the differences between the modelled rainfall responses over both the US and northern South America. Further modelling studies will be required for this analysis and including a more detailed comparison of the respective land-surface schemes used by each of the models.

The historical Atlantic decadal variability did not occur in isolation however, and further study is required to examine how the climate responds to decadal Atlantic variability in the presence of similar timescale variability in other ocean basins (e.g. the Indian ocean). Additionally, the sensitivity of North American moisture transport to the detailed nature of Atlantic SST, as discussed by Wang et al. (2007) and Wang et al. (2008) demonstrate that there is a need to explore further the sensitivity of the climate response to changes in the magnitude, spatial extent, and sign of SST forcing patterns.

As with all modelling studies that prescribe SSTs as a boundary condition, there remain uncertainties concerning the extent to which the results will accurately reflect the true behaviour of the full coupled system (see e.g. Bretherton and Battisti 2000; Copsey et al. 2006). The similarity of responses seen in the model results and the observational composites, gives some grounds for optimism, but further evidence of the validity of these results will only be obtained through the use of atmosphere-ocean coupled models and atmosphere-mixed layer coupled models (e.g. Zhang et al. 2007).

Acknowledgments This work was supported by the European Union Framework 6 DYNAMITE project (Contract Number 003903GOCE) and by the NERC NCAS-Climate programme. Rowan Sutton is supported by a research fellowship from the Royal Society. We would also like to thank our colleagues at the Met Office Hadley Centre and the Climatic Research Unit for the use of their gridded observational datasets: http://www.metoffice.gov.uk/hadobs.

\section{References}

Bader J, Latif M (2003) The impact of decadal-scale Indian ocean sea surface temperature anomalies on Sahelian rainfall and the North Atlantic oscillation. Geophys Res Lett 30(22):2169-2173

Basnett T, Parker D (1997) Development of the global mean sea level pressure data set GMSLP2. Hadley Centre Climate Research Technical Note CRTN 79, Hadley Centre, Met Office, FitzRoy Rd, Exeter, Devon, EX1 3PB, UK

Bretherton C, Battisti D (2000) An interpretation of the results from atmospheric general circulation models forced by the time history of the observed sea surface temperature distribution. Geophys Res Lett 27(6):767-770

Brohan P, Kennedy J, Harris I, Tett S, Jones P (2006) Uncertainty estimates in regional and global observed temperature changes: a new dataset from 1850. J Geophys Res 111(D12106). doi: 10.1029/2005JD006,548
Collins WD, Rasch PJ, Boville BA, Hack JJ, McCaa JR, Williamson DL, Briegleb BP, Bitz CM, Lin SJ, Zhang M (2006) The formulation and atmospheric simulation of the community atmosphere model version 3 (CAM3). J Clim 19(11):2144-2161

Copsey D, Sutton R, Knight J (2006) Recent trends in sea level pressure in the Indian ocean region. Geophys Res Lett 33

Cox PM, Harris PP, Huntingford C, Betts RA, Collins M, Jones CD, Jupp TE, Marengo JA, Nobre CA (2008) Increasing risk of Amazonian drought due to decreasing aerosol pollution. Nature 453(7192):212-215. doi:10.1038/nature06960

Curtis S, Gamble DW (2008) Regional variations of the Caribbean mid-summer drought. Theor Appl Climatol 94(1):25-34. doi: 10.1007/s00704-007-0342-0

Déqué M, Dreveton C, Braun A, Cariolle D (1994) The Arpege/IFS atmosphere model: a contribution to the French community climate modelling. Clim Dyn 10(4-5):249-266

Enfield D, Mestas-Nunez A, Trimble P (2001) The Atlantic multidecadal oscillation and its relation to rainfall and river flows in the continental US. Geophys Res Lett 28(10): 2077-2080

Folland C, Parker D, Palmer T (1986) Sahel rainfall and worldwide sea temperatures. 1901-1985. Nature 320:602-607

Folland C, Colman A, Rowell D, Davey M (2001) Predictability of northeast Brazil rainfall and real-time forecast skill, 1987-1998. J Clim 14(9):1937-1958

Gamble DW, Parnell DB, Curtis S (2008) Spatial variability of the Caribbean mid-summer drought and relation to North Atlantic high circulation. Int J Climatol 28(3):343-350. doi:10.1002/joc. 1600

Giannini A, Saravanan R, Chang P (2003) Oceanic forcing of Sahel rainfall on interannual to interdecadal time scales. Science 302(5647): 1027-1030

Gill A (1980) Some simple solutions for heat-induced tropical circulation. Q J Roy Meteor Soc 106:447-462

Goldenberg SB, Landsea CW, Mestas-Nunüez AM, Gray WM (2001) The recent increase in Atlantic hurricane activity: causes and implications. Science 203:474-479

Hoerling M, Hurrell J, Eischeid J, Philips A (2006) Detection and attribution of twentieth-century northern and southern African rainfall change. J Clim 19(16):3989-4008

Hulme M (1992) A 1951-1980 global land precipitation climatology for the evaluation of general-circulation models. Clim Dyn $7(2): 57-72$

Knight JR (2008) The Atlantic multidecadal oscillation inferred from the forced climate response in coupled general circulation models. J Clim preprint. doi:10.1175/2008JCLI2628.1

Knight J, Allan R, Folland C, Vellinga M, Mann M (2005) A signature of persistent natural thermohaline circulation cycles in observed climate. Geophys Res Lett 32

Knight J, Folland C, Scaife A (2006) Climate impacts of the Atlantic multidecadal oscillation. Geophys Res Lett 33:L17. doi:10.1029/ 2006GL026242

Li L, Wang B, Zhou T (2007) Contributions of natural and anthropogenic forcings to the summer cooling over eastern China: an AGCM study. Geophys Res Lett 34(L18807)

McCabe G, Palecki M, Betancourt J (2004) Pacific and Atlantic Ocean influences on multidecadal drought frequency in the United States. Proc Natl Acad Sci 101(12):4136-4141

Moura A, Shukla J (1981) On the dynamics of droughts in northeast Brazil: observations, theory and numerical experiments with a general circulation model. J Atmos Sci 38(12): 2653-2675. doi:10.1175/1520-0469(1981)038<2653:OTDODI $>2.0$. $\mathrm{CO} ; 2$

Navarra A, Gualdi S, Masina S, Behera S, Luo JJ, Masson S, Guilyardi E, Delecluse P, Yamagata T (2008) Atmospheric horizontal resolution affects tropical climate variability in coupled models. J Clim 1(4):730-750. doi:10.1175/2007JCLI1406.1 
Okumura Y, Xie SP, Numaguti A, Tanimoto Y (2001) Tropical Atlantic air-sea interaction and its influence on the NAO. Geophys Res Lett 28(8):1507-1510

Okumura Y, Deser C, Hu A, Timmerman A, Xie SP (2008) North Pacific climate response to freshwater forcing in the Subartic North Atlantic: ocean and atmospheric pathways. J Clim (Submitted)

Peixoto J, Oort A (1993) Physics of climate. American Institute of Physics

Pope V, Gallani M, Rowntree P, Stratton R (2000) The impact of new physical parametrizations in the Hadley centre climate model: HadAM3. Clim Dyn 16(2-3):123-146

Rayner N, Parker D, Horton E, Folland C, Alexander L, Rowell D, Kent E, Kaplan A (2003) Global analyses of SST, sea ice and night marine air temperature since the late nineteenth century. J Geophys Res Atmos 108(D14):4407. doi:10.1029/2002JD002670

Roeckner E, Brokopf R, Esch M, Giorgetta M, Hagemann S, Kornblueh L, ad U Schilzweida US, Manzini E (2004) The atmospheric general circulation model Echam5, Part II: sensitivity of simulated climate to horizontal and vertical resolution. Max Planck Institute Report 354

Roeckner E, Brokopf R, Esch M, Giorgetta M, Hagemann S, Kornblueh L, Manzini E, Schlese U, Schulzweida U (2006) Sensitivity of simulated climate to horizontal and vertical resolution in the Echam5 atmosphere model. J Clim 19(16): 3771-3791

Rotstayn LD, Lohmann U (2002) Tropical rainfall trends and the indirect aerosol effect. J Clim 15(15):2103-2116

Shapiro L, Goldenberg S (1998) Atlantic sea surface temperatures and tropical cyclone formation. J Clim 11:578-590
Sutton R, Hodson D (2003) Influence of the ocean on North Atlantic climate variability 1871-1999. J Clim 16(20):3296-3313

Sutton R, Hodson D (2005) Atlantic Ocean forcing of North American and European summer climate. Science 309:115-118

Sutton R, Hodson D (2007) Climate response to a multidecadal warming and cooling of the North Atlantic Ocean. J Clim 20(5): 891-907

Uvo C, Repelli C, Zebiak S, Kushnir Y (1998) The relationships between tropical Pacific and Atlantic SST and northeast Brazil monthly precipitation. J Clim 11(4):551-562

Wang S, Zhou T, Cai J, Zhu J, Xie Z, Gong D (2004) Abrupt climate change around $4 \mathrm{ka}$ bp: role of the thermohaline circulation as indicated by a GCM experiment. Adv Atmos Sci 21(2):291-295

Wang C, Lee SK, Enfield D (2007) Impact of the Atlantic warm pool on the summer climate of the western Hemisphere. J Clim 20(20):5021-5040

Wang C, Lee SK, Enfield DB (2008) Climate response to anomalously large and small Atlantic warm pools during the summer. J Clim 21(11):2437-2450. doi:10.1175/2007JCLI2029.1

Zhang R, Delworth TL, Held IM (2007) Can the Atlantic Ocean drive the observed multidecadal variability in northern hemisphere mean temperature? Geophys Res Lett 34:L02,709+. doi:10.1029/ 2006GL028683

Zhou J, Lau KM (2001) Principal modes of interannual and decadal variability of summer rainfall over South America. Int J Climatol 21:1623-1644

Zhou T, Yu R, Li H, Wang B (2008) Ocean forcing to changes in global monsoon precipitation over the recent half-century. J Clim 21:3833-3852 